\title{
La dignidad humana como eje transversal para el ejercicio del derecho a la salud
}

\section{Claudia Patricia Orellana Robalino*}

Recibido: 26 enero 2017

\begin{abstract}
Resumen
Dignidad humana, cimiento de los derechos fundamentales, entre ellos los derechos económicos, sociales y culturales (DESC) que incluye el derecho a la salud, actúa de forma transversal al momento de interpretarlos. El derecho a la salud fue clasificado como derecho de segunda generación operando de forma progresiva para el desarrollo de los derechos de primera. Esta interpretación es obsoleta, pues el Comité de DESC de la ONU declara el status de fundamental de los DESC en la Proclamación de Teherán de 1968 ( N¹3) y la Declaración de Viena de 1993 (N5). A pesar de este reconocimiento formal del derecho a la salud, parte de los Derechos Económicos Sociales y Culturales como fundamental, en la práctica no existe una exigibilidad directa de este y se demuestra con la presentación de casos fundamentados en la violación al derecho a la vida y a la integridad personal, cuando encuadran en la violación al derecho a la salud.
\end{abstract}

Palabras clave: Dignidad humana, derecho a la salud, principios generales del derecho, normas imperativas, ius cogens.

\section{Human dignity as transversal axis to compliance the right to health}

\begin{abstract}
Human dignity, foundation of fundamental rights, as well as economic, social and cultural rights (ESCR) including the right to the health, acts as transversal axis to compliance the right to health. The right to health was classified as second human generation right, which operated gradually for the progress of first generation human rights. This interpretation is obsolete, as the Committee on ESCR of UN gives them the status of fundamental rights in
\end{abstract}

*Universidad de las Américas. Quito, Ecuador. claudia.orellana@gmail.com 
the proclamation of Tehran of 1968 (No.13) and the Vienna Declaration of 1993 (No.5).

Despite this formal recognition of the right to health as fundamental right, part of Economic Social and Cultural Rights, the practice at courts shows there isn't a direct enforceability of the right to health. This is proved by the submit of cases based on the violation of the right to life and personal integrity, when in fact they fall in the violation of the right to health.

Key words: Human dignity, right of health, general principles of law, peremptory norm, jus cogens.

\section{Sumario}

I. Introducción II. Evolución del concepto de dignidad humana y derecho a la salud. 2.1. Análisis del concepto de dignidad humana. 2.1.1 Edad antigua (4000 A.C- S.V) 2.1.2 Edad media (S.V- 1453) 2.1.3 Edad moderna (1453- 1789) 2.1.4 Edad contemporánea (1789-actualidad) 2.2 Análisis del concepto del derecho a la salud. III. Interpretación de la dignidad humana y el derecho de salud en casos a nivel internacional y regional. 3.1 Internacional: caso D. vs. Reino Unido resuelto por TEDH1 en 1996. 3.2 Regional: Caso Gonzáles Lluy y otros vs. Ecuador sentencia emitida por la Corte IDH en el año de 2015. IV. La dignidad humana como eje transversal para ejercicio del derecho a la salud. Conclusiones. Bibliografía.

\section{Introducción}

El presente ensayo es de tipo explicativo y descriptivo cuyo objetivo principal es exponer el principio de la dignidad humana como eje transversal para el ejercicio e interpretación del derecho a la salud. Está compuesto de tres argumentos que son: 1) Evolución histórica del concepto de dignidad humana y derecho a la salud, se considera pertinente analizar la evolución de estos conceptos, pues su concepto, definición e interpretación dependen del contexto histórico-cultural y la realidad material de la época demostrando su característica de dinámicos. 2) Estudio de dos casos a nivel internacional el del Sr. D vs. Reino Unido resuelto por el Tribunal Europeo de Derechos Humanos (TEDH) en 1996 y a nivel regional el caso de

1 El TEDH es la autoridad judicial perteneciente al Consejo de Europa y uno de sus objetivos es garantizar el ejercicio de los derechos humanos reconocidos en la Convención para la protección de los Derechos humanos y las libertades de 1950. 
Gonzáles Lluy y otros vs. Ecuador sentencia emitida por la Corte Interamericana de derechos fundamentales (CorteIDH) en el 2015. Se estudia estos casos con el objetivo de identificar cómo se interpretó el principio de dignidad humana y el derecho a la salud, se verifica si el derecho a la salud se interpreta de forma independiente o conexa (subordinada) a los derechos civiles y políticos de la vida o integridad personal. El método que se utiliza es el de "case Brief" o resumen del caso, debido a que permite sintetizar la información relevante de un caso en pocos párrafos. 3) El último argumento tiene como objetivo informar y explicar cómo actúa el principio de dignidad humana al momento de interpretar y aplicar los derechos fundamentales, a su vez se analiza y expone la premisa que tanto el principio de dignidad humana como el derecho a la salud son principios generales del derecho, cuya característica principal es ser "ius cogens" y se explica que a pesar de ser principios generales del derecho actúan de forma diferente, conforme lo señalado por la clasificación de los principios generales del derecho de Manuel Atienza y Jorge Ruiz Mancero.

\section{Evolución del concepto de dignidad humana y derecho a la salud.}

2.1 Análisis del concepto de dignidad humana: el concepto de dignidad humana existe a lo largo de la historia, sin embargo, es un concepto dinámico que se transforma conforme el contexto histórico y socio cultural ${ }^{2}$. A continuación, se presenta, de forma histórica, algunas definiciones de dignidad humana:

2.1.1 Edad antigua (4000 A.C- S.V): El concepto de dignidad humana estuvo presente en las civilizaciones griegas, romanas, judeo-cristianas, entre otras. Como ejemplos tenemos las definiciones de:

\footnotetext{
$2 \mathrm{Al}$ respecto Jürgen Habermas señala que: "La experiencia de retos históricos específicos, diferentes aspectos del significado de la dignidad humana surgen desde la plétora de experiencias de lo que significa ser humillado y herido profundamente.”. Jürgen Habermas. El concepto de dignidad humana y la utopía realista de los derechos humanos. México, Diánoia, volumen LV, número 64, mayo 2010, p.8.
} 


\section{A. Antigua Roma:}

Cicerón: "Lo que tu sabiduría y a la grandeza de tu animo toca, es hacer cuenta que todo tu lustre y dignidad está fundada en tu propia virtud y propios hechos, y en el ser y autoridad de tu persona. (...) Este poder y honra fue alcanzado con haber hecho en la República muy buenas hazañas y esclarecidas"

B. Dignidad heterónoma de San Agustín: La noción de dignidad heterónoma se refiere a la dignidad de origen externo, basada en la imagen de Dios o en la dignidad como honor, cargo o título. Depende de los elementos exógenos que neutralizan la libertad individual y la igualdad entre los humanos. ${ }^{4}$

Del análisis de estas definiciones se desprende que el concepto de dignidad humana "dignita hominis" en la edad antigua, se lo percibe como algo externo, que le da un valor al ser humano, por su posición social, participación política y logros alcanzados. En la antigua Roma este valor es dado al ser humano, ya que posee un rango superior entre los otros seres del Cosmos, que se relaciona con el nivel de autoridad y los méritos realizados a favor de la República, dentro de una sociedad jerárquica, ${ }^{5}$ mientras que en la visión de San Agustín la dignidad humana deriva de su sumisión a Dios, ya que el ser humano no posee razón autónoma, depende de la razón de Dios, mediante la obediencia para trascender. La dignidad humana en ambos autores, se da en un contexto jerárquico.

2.1.2 Edad media (S.V-1453): Durante se gesta el discurso centrado en la “dignitas hominis" y de la "miseria hominis", pero no desde una concepción

3 Marco Tulio Cicerón. Epistolas familiares, tomo VII, 1884. España: Central y estereotipia, 1884, pp. 10-28 4 Gregorio, Peces-Barba Martínez. La dignidad de la persona desde la filosofía del derecho. España: Dykinson, 2003, p.27)

5 "En Roma la dignidad se relaciona con la nobleza, con la función desempeñada, con los méritos alcanzados por los servicios públicos. Es un reconocimiento de la comunidad, vinculado al comportamiento del individuo en sociedad Por eso la dignidad implica, en una sociedad de clases, una jerarquía superior por encima del vulgo para el emperador, nobles, clases altas, etc., a la que acompañaba una auctoritas. Las personas con autoridad son llamadas dignitantes. Javier de la Torres, Díaz. Dignidad humana y bioética. España: Universidad Pontifica Comillas, 2008, p.13. 
de la antigua Roma $^{6}$, esta nueva concepción establece que el ser humano es responsable por su dignidad y miseria, debido a que posee autonomía y razón, que deriva de su semejanza con Dios. Se sigue con dos ejemplos del concepto de la dignidad:

A. Santo Tomás de Aquino: señala que el ser humano posee una dignidad natural y razón, pues es obra y semejanza de Dios, quien en conjunto del uso de la razón propia más la razón Divina, y su característica de elegir de forma autónoma su conducta comprende la dignidad del otro y obtiene la libertad de perseguir fines superiores. ${ }^{7}$

La postura de Santo Tomás de Aquino reconoce la dignidad humana por ser semejantes a Dios y lo hace de forma universal, para todas las criaturas racionales creadas a semejanza de Dios.

B. Pedro Abelardo: Defiende la importancia del principio de autonomía y la existencia de la razón humana ${ }^{8}$, porque al ejercerla se experimenta la realidad por la que se conoce a Dios, entonces estas características propias del ser humano es lo que constituye la dignidad humana, que, a diferencia de San Agustín, cuando falta la voluntad no puede haber pecado y en consecuencia no es indigno, es decir el humano puede elegir entre ser digno o indigno.

Al analizar estas dos posturas se manifiesta que durante la edad media continua el modelo de dignidad humana basado en la semejanza del ser humano con Dios, por lo tanto, es una característica natural, se sustenta en el ius naturalismo. La semejanza de ambas posturas es el reconocimiento de la autonomía humana y la razón, con característica innata.

2.1.3 Edad moderna (1453- 1789): El concepto metafísico de dignidad

\footnotetext{
6 La concepción "dignitas hominis" de la antigua Roma era aquella descrita por Cicerón, que considera el valor del individuo en relación de los cargos que ostentaba en la sociedad. Marco Tulio Cicerón. Epístolas familiares, tomo VII, 1884. España: Central y estereotipia, 1884, pp. 15-28.

7 Santo Tomas de Aquino. Suma Teológica. España: Biblioteca de autores cristianos, 2001, p.320-327.

8 Pedro Abelardo señala que: "recusa cualquier miseria en el hombre y defiende la libertad del espíritu, que en conjunto con la razón son características de dignidad humana". Antonio, Pele. Modelos de la dignidad del ser humano en la edad media. España: Universidad Calos III de Madrid, 2010, p.27.
} 
humana proveniente de la semejanza con Dios es reemplazado por el reconocimiento consensuado ${ }^{9}$ de la existencia de racionalidad en los seres humanos, característica que la diferencia de los animales y por la cual son considerados gozan de dignidad. A continuación, se sigue con dos visiones de dignidad de la edad moderna:

A. John Locke: la dignidad humana existe por el reconocimiento consensuado de los ciudadanos, a través del pacto social, de la racionalidad y libertad humana como característica principal que los distingue de los animales. La soberanía proviene de los ciudadanos, que de forma voluntaria y con uso de su razón deciden unirse para crear un Estado que les brinde seguridad, por lo tanto, los ciudadanos poseen derechos irrenunciables, previos a la existencia del Estado que deben ser respetados, como su libertad, propiedad privada y la vida, derechos que les permiten mantener su estatus de dignidad. ${ }^{10}$ El pensamiento de John Locke inspiro en Inglaterra la declaración de derechos o "Bill of rights" de 1689.11

B. Rousseau: al igual que John Locke reconoce la dignidad humana como valor de la persona, presente en el estado de naturaleza de los individuos, en consecuencia, todos son titulares de dignidad humana, por lo tanto, gozan de derechos naturales que no pueden ser violentados por el Estado, pues al ser creación de los individuos, su papel es de protección y garantía de dichos derechos, que le permiten gozar de dignidad. Las ideas de Rousseau influyen en la Revolución Francesa. ${ }^{12}$

Al analizar en conjunto estas dos visiones sobre la dignidad humana se infiere son similares, ya que parten de la idea de un estado natural del ser humano, antes de la sociedad organizada como Estado, en cual ya gozaba de dignidad y de

\footnotetext{
9 Es consensuada por el conjunto de individuos que forman parte del contrato social, independiente de la existencia de Dios, se niega el origen divino del poder, en esta visión existe el poder por el pacto social de los ciudadanos.

10 Miguel Ángel, Polo Santilla. Ética y política de Locke: de los derechos humanos a los humanos sin derechos. Perú: Universidad San Martín de Porres, 2010, pp.3-6.

11 "tal como sus antepasados, generalmente lo han hecho, se reivindica y hace valor su dignidad y antiguos derechos." Bill of rights, 1689, p.5.

12 Miguel Ángel, Polo Santilla. Ética y politica de Locke: de los derechos humanos a los humanos sin derechos. Perú: Universidad San Martín de Porres, 2010, p.4.
} 
derechos naturales de forma independiente de la existencia de Dios. Los humanos son criaturas sociales, quienes de forma libre y voluntaria se organizaron en un Estado, cuyo fin es garantizar la dignidad humana, a través del ejercicio de los derechos naturales.

2.1.4 Edad contemporánea (1789-actualidad): Los cambios a finales de la edad moderna a partir de la Declaración de derechos de 1689 de Inglaterra, la Declaración de derechos de Virginia 1776, la Declaración de Independencia de Estados Unidos 1776, La Declaración de derechos del hombre y del ciudadano 1789, la Declaración Universal de Derechos humanos 1948, la Declaración Americana de Derechos humanos 1945 marcan el precedente histórico para la edad contemporánea, ya que para la mayoría de tratadistas jurídicos inicia la historia de los derechos humanos en lo que se conoce como la etapa de "Las Grandes Declaraciones"13, basadas en cambios sociales profundos que buscan garantizar la dignidad humana y los derechos de los ciudadanos. Es así que a finales del S. XVIII el concepto de dignidad humana es el núcleo del concepto de derechos humanos, ya que se justifica la existencia de estos en el principio de dignidad humana, positivado a través de instrumentos legales. ${ }^{14}$.Se toma dos definiciones de la edad contemporánea sobre la dignidad humana que son:

Immanuel Kant: define el concepto de dignidad como un requerimiento ético e imperativo categórico, que exige tratar a toda persona como un fin en sí mismo. Las palabras de Kant son las siguientes:

“Todo tiene o un precio o una dignidad. Lo que tiene un precio puede ser sustituido por otra cosa como equivalente; en cambio, lo que se halla por encima de todo precio y, por tanto, no admite equivalente, posee dignidad"'15

A. Jürgen Habermas: la dignidad humana es un valor ético que forma parte del ser humano al respecto señala que

13 Carlos Tünnermann. Los Derechos Humanos evolución histórica y reto educativo. Venezuela: UNESCO, tercera edición, 2006, p.8.

14 Ibídem, p. 8.

15 Kant, Immanuel. Kant's moral philosophy. Estados Unidos: The Chaucer press, 2003, p.74. 
“(...) la dignidad humana configura el portal a través del cual el sustrato igualitario y universalista de la moral se traslada al ámbito del derecho. La idea de la dignidad humana es el eje conceptual que conecta la moral del respeto igualitario de toda persona con el derecho positivo y el proceso de legislación democrático, de tal forma que su interacción puede dar origen a un orden político fundado en los derechos humanos (...) Siempre ha existido-aunque inicialmente de modo implícito- un vínculo conceptual interno entre los derechos humanos y la dignidad humana. Nuestra intuición nos dice, en cualquier caso, que los derechos humanos han sido producto de la resistencia al despotismo, la opresión y la humillación." 16

El pensamiento de estos dos autores, influye en la época de las grandes declaraciones, ya que considera a la dignidad humana como principio universal de la ética (Habermas) o imperativo categórico (Kant), aplicable a todos los seres humanos de forma universal. El concepto de dignidad humana está vinculado, de forma estrecha a la ética, como un principio, reconocido por diferentes culturas, pero es a partir de la Declaración Universal de Derechos Humanos de 1948, que se reconoce como principio legal "ius cogens" vinculante a los Estados miembros que han firmado y ratificado dicho instrumento internacional. ${ }^{17}$ Se sigue que el principio de dignidad humana es cimiento de los derechos fundamentales ${ }^{18}$, que son protegidos por un Estado democrático y sus ciudadanos al reconocer y respetar la autonomía, libertad y razonamiento propio y de otros. ${ }^{19}$

16 Habermas señala que: "por una parte, (a) la función mediadora de la "dignidad humana" en el cambio de perspectiva que tuvo lugar con el paso de los deberes morales a exigencias legales, y por otra, (b) la paradójica generalización de un concepto de dignidad que no estaba originalmente orientado a la distribución igualitaria de la dignidad, sino que, por el contrario, servía como indicador de diferencias de estatus, basadas en factores como la raza, sexo, étnica, género, entre otros." Jürgen, Habermas. El concepto de dignidad humana y la utopía realista de los derechos humanos. México, Diánoia, volumen LV, $\mathrm{N}^{\circ} 4,2010$, p.12.

17 Para Habermas la universalización del concepto de dignidad humana debe seguir a la individualización, es decir el reconocimiento de factores como la raza, género, etnia, posición económica que deben ser tomados en cuenta para garantizar el derecho a la dignidad humana. Jürgen, Habermas, El concepto de dignidad humana y la utopía realista de los derechos humanos. México, Diánoia, volumen LV, N 4,2010, p.16.

18 "Reconociendo y afirmando que todos los derechos humanos tienen su origen en la dignidad y el valor de la persona humana" Declaración y programa de acción de Viena, 1993, p.1.

19 Para Kant esa capacidad de reconocer la libertad, autonomía y razonamiento propio y de otro es tener dignidad y en sus palabras "tratar así mismo y a todos los demás nunca como un simple medio, sino siempre al mismo tiempo como fines en sí mismos." Immanuel, Kant. Kant's moral philosophy. Estados Unidos: The 
De manera informativa y al no ser el tema principal de este ensayo, se menciona que una de las discusiones más relevantes, en la actualidad, sobre el principio de dignidad humana son las tensiones en cuanto: i) Ser considerada el cimiento de los derechos fundamentales. ii) Tiene un carácter natural o artificial. ii) Si es abstracta o concreta y iii) Si es universal o particular. ${ }^{20}$ Miguel Carbonell al respecto de la tensión sobre la universalidad de la dignidad humana señala:

"La universalidad de los derechos debe ser contemplada también desde una óptica política, a partir de la cual dicha característica supondría a la idea de que todos los habitantes del planeta con independencia del país en que hayan nacido y del lugar del globo en el que se encuentran debería tener al menos el mismo núcleo básico de derechos fundamentales, los cuales además tendrían que ser respetados por todos los gobiernos. Desde luego, la forma en que ese núcleo básico podría plasmarse en los distintos ordenamientos jurídicos no tiene que ser uniforme, para estar de acuerdo con los principios de justicia; la historia, cultura y pensamiento de cada pueblo o comunidad puede agregar y de hecho históricamente ha agregado, una multiplicidad de matices y diferencias al conjunto de derecho fundamentales que establece su respectiva constitución." 21

En este ensayo se adopta la visión de Jürgen Habermas que considera a la dignidad humana como valor ético o "portal" entre la moral y el derecho, que sustenta un orden jurídico y político basado en derechos humanos, por lo tanto, es un principio general del derecho. Así mismo se está de acuerdo con la opinión de Carbonell al señalar que la dignidad humana es universal, pero debe ser adaptada a la realidad de cada Estado, en consecuencia, las discusiones sobre las tensiones de la dignidad humana no son excluyentes entre sí.

2.2 Análisis del concepto del derecho a la salud: La salud humana durante las diferentes etapas de la historia es uno de los principales temas de discusión, sin

Chaucer press, 2003, p.74.

20 Viviana Bohórquez Monsalve y Javier Aguirre Román, Las tensiones de la dignidad humana: conceptualización y aplicación en el derecho internacional de los derechos humanos. Revista Sur, V. 6, №11, 2009, pp.41-42. Los autores señalan que estas tensiones se encuentran íntimamente relacionadas.

21 Miguel, Carbonell. Derechos humanos: origen y desarrollo. Ecuador: Librería jurídica Cevallos, 2013, p.20. 
embargo, a partir de la edad contemporánea durante el S. XIX adquiere mayor importancia, ya que hubo un desarrollo importante de la Salud pública al impulsar y publicar leyes de salud en Reino Unido, Estados Unidos, Alemania, entre otros. Más tarde con la constitución de la Organización Mundial de la Salud (OMS) en 1948, como organismo internacional para promover, prevenir, intervenir y desarrollar esfuerzos a nivel mundial sobre la salud pública ${ }^{22}$ se armonizan y codifican principios rectores y definiciones de salud.

El documento de Constitución de la OMS en sus inicios definía a la salud como la ausencia de enfermedad, no obstante, ha sido modificado varias veces, y la última se realizó en el 2014, se toman el concepto de salud de dicho documento: "La salud es un estado de completo bienestar físico, mental y social y no solamente la ausencia de afecciones o enfermedades" 23

El derecho a la salud es parte de los DESC o de segunda generación, cuyo antecedente histórico principales son las revoluciones de las clase trabajadora $\mathrm{u}$ obrera, a partir del siglo XIX, que reclama por sus derechos laborales, sociales, económicos entre otros, en respuesta a la clase dominante, que controlaba el capital. ${ }^{24}$. Los DESC son positivados en el Pacto Internacional de Derechos económicos, sociales y culturales de 1966 (PIDESC).

El derecho a la salud ha sido considerado como un derecho no fundamental de carácter secundario que permite la realización de los derechos civiles y políticos, mediante el desarrollo de la idea de conexión con el ejercicio del derecho a la vida y a la integridad personal ${ }^{25}$, no obstante en la actualidad se considera es un derecho autónomo, porque no depende de otro derecho para existir, en consecuencia es igual que todos los derechos fundamentales es autónomo, inalienable e independiente, de igual jerarquía y reconocido a nivel mundial. ${ }^{26}$

Los DESC complementan a los derechos civiles y políticos para en conjunto

22 La OMS define a la salud pública como "La ciencia y arte de promover la salud, prevenir las enfermedades y prolongar la vida a través de esfuerzos organizados de la sociedad" OMS. Glosario de promoción de la salud. Suiza: 1998, p.12.

23 Organización mundial de la Salud (OMS). Documentos básicos de la OMS. Suiza: OMS, 2014, p.1.

24 Gregorio, Peces-Barba Martínez. Lecciones de derechos fundamentales. España: Dykinson, 2015, p.114.

25 Diana, Quintero. La salud como derecho. Colombia: Panamericana formas e impresos, 2011, pp. 79-80. 26 Proclamación de Teherán, 1968, párr. 13. 
y sin estar subordinados unos a otros hacer una realidad la dignidad humana. A partir del reconocimiento de los DESC se deriva que el papel del Estado, ya no es únicamente, el de respetar los derechos civiles y políticos (obligación negativa), ahora debe garantizar el mínimo de condiciones necesarias que permitan el ejercicio de los derechos económicos, sociales y culturales (obligación positiva). ${ }^{27}$ En el Ecuador el derecho a la salud se encuentra reconocido en la Constitución actual en el Art. 32 que dice:

La salud es un derecho que garantiza el Estado, cuya realización se vincula al ejercicio de otros derechos, entre ellos el derecho al agua, la alimentación, la educación, la cultura fisica, el trabajo, la seguridad social, los ambientes sanos y otros que sustentan el buen vivir." 28

El Comité de derechos económicos, sociales y culturales (Comité DESC) de la ONU en su observación general $N^{\circ} 14$ del 2000 analiza el alcance del Art. 12 del PIDESC y señala que el derecho a la salud abarca libertades y derechos como: la libertad personal de controlar la salud y su cuerpo, de decidir si accede a un servicio público o privado, a no ser sometido a torturas, tratamientos y experimentos no consensuales, el acceso a un seguro de salud y el cumplimiento de ciertos elementos esenciales e interrelacionados que son: a) Disponibilidad: el Estado deberá contar con un número suficiente de establecimientos de bienes y servicios públicos de salud. b) Accesibilidad: los establecimientos, bienes y servicios de salud deben ser accesibles a todos sin discriminación alguna. c) Aceptabilidad: todos los establecimientos, bienes y servicios de salud deberán ser respetuosos de la ética médica y culturalmente apropiados. d) Calidad: los establecimientos, bienes y servicios de salud deberán ser también apropiados desde el punto de vista cientifico, médico y ser de buena calidad. ${ }^{29}$

27 "En la nueva perspectiva del Estado Social, se asume la necesidad de brindar a la población un mínimo básico de bienestar que se compromete a entregar el Estado a través de prestaciones positivas. Es por esto que el derecho a la salud es considerado como un derecho prestacional. Humberto, Nogueira. El derecho a la igualdad ante a la ley, la no discriminación y acciones positivas. Revista de derecho universidad católica del norte, V. $13, \mathrm{~N}^{\circ} 2$, pp.63-66.

28 Constitución de la República del Ecuador, 2008, Art.32.

29 Comité de derechos económicos, sociales y culturales (Comité DESC) de la ONU, observación general $N^{\circ}$ 
El derecho a la salud ha sido definido en varios instrumentos internacionales, que sirvieron de referencias para este apartado, dichas definiciones se encuentran disponibles en el Anexo 1, cuadro 2 disponible en el siguiente link: https:// sedesde.worldsecuresystems.com/anexo

\section{Interpretación de la dignidad humana y el derecho de salud en casos a nivel internacional y regional.}

Se analizan dos casos sobre la exigibilidad del derecho a la salud con el objetivo de identificar cómo se interpretó dicho derecho, si se lo hace de una forma autónoma o dependiente al cumplimiento de los derecho civiles o políticos, es por esta razón que se enfatiza en analizar la resolución del caso únicamente en el ámbito del ejercicio del derecho a la salud y la interpretación de la dignidad humana. El método que se utiliza es el de "Case Brief" o resumen del caso, debido a que permite condensar en pocos párrafos la resolución de una Corte sobre los elementos principales analizados. A nivel internacional se analiza el caso del Sr. D vs. Reino Unido resuelto por el TEDH en 1996 y a nivel regional el caso Gonzáles Lluy y otros vs. Ecuador sentencia emitida por la CorteIDH

\subsection{Internacional: caso D. vs. Reino Unido resuelto por TEDH30 en 1996.}

El caso es presentado por el señor "D" ciudadano de la Isla de San Cristóbal, quien había ingresado a Inglaterra en Reino Unido en 1993, pero fue detenido por tráfico de drogas ilegales, enjuiciado y condenado a prisión por 6 años, sin embargo, se redujo su sentencia por buen comportamiento y obtuvo permiso para salir el 24 de enero de 1996, fue llevado a un centro de detención de inmigrantes para su deportación a San Cristóbal. En 1994 mientras cumplía su condena, el Sr. D sufrió neumonía, fue llevado al hospital y se le diagnostico con síndrome

14. Ginebra: $O N U, 2000$, pp.3-4.

30 El TEDH es la autoridad judicial perteneciente al Consejo de Europa y uno de sus objetivos es garantizar el ejercicio de los derechos humanos reconocidos en la Convención para la protección de los Derechos humanos y las libertades de 1950. 
de inmune deficiencia adquirido (sida), conforme el diagnóstico y el deterioro de su salud los médicos concluyeron que la infección fue adquirida varios años atrás. Antes de ser liberado el Sr. D solicito al secretario de Estado que no se lo deporte a su país natal, ya que su condición médica y su estado de salud eran delicados y deportarlo implicaría la pérdida de atención médica que estaba recibiendo acortando su esperanza de vida. Esta solicitud de permiso de entrada y permanencia en Inglaterra fue negada, razón por la cual presentó un recurso de revisión ante la Alta Corte de Inglaterra, que fue negado, motivo por el cual presentó un recurso de apelación, que desestimo su solicitud alegando que la ley de inmigración de Reino Unido de 1971 establecía claramente: i) Distinción entre el permiso de entrada y salida y el permiso de entrada y permanencia. ii) El Sr. D solicitó un permiso de entrada y permanencia y la ley de inmigración establece los requisitos para otorgar dicho permiso, requisitos que el Sr. D no cumplía, pues había cometido el delito de tráfico de drogas ilegales que atenta contra la seguridad y salud pública, bajo estas circunstancias es imposible otorgarle el permiso.

El señor D presento su caso ante el TEDH manifestando que se han violado sus derechos contenidos en el Convenio Europeo de Derechos humanos tales como: a la vida (Art. 2), prohibición de tortura (Art. 3), a la vida privada y familiar (ART. 8) y derecho a un recurso efectivo (Art.13). La pretensión del Sr. D es que se restituyan sus derechos y pueda permanecer en Inglaterra, para continuar con el tratamiento gratuito para su enfermedad.

El TEDH concluyó que: i) Deportar al Sr. D a su ciudad de origen ocasionaría la responsabilidad del Estado demandado por violar la prohibición de no tortura dispuesta en el Art. 3 de la Convención Europea de Derechos Humanos. ${ }^{31}$ ii) Deportarlo sería un trato cruel inhumano y degradante (Art. 3 de la Convención Europea de DD.HH.), pues afecta, de forma directa, a su dignidad humana, al despojarlo de un tratamiento gratuito para el VIH/SIDA ya que al enviarlo a su país de origen le impediría tener una muerte digna y sin dolor, pues las infecciones efecto del sida sin un tratamiento adecuado degeneran el estado de salud físico, mental y social, es así que se impide de esta forma el acceso a

31 Prohibición de la tortura "Nadie podrá ser sometido a tortura ni a penas o tratos crueles, inhumanos o degradantes. Convención Europea de Derechos humanos, Art. 3, 1950, p.6. 
la salud pública, que en el caso de Reino Unido cuenta con la infraestructura, medicamentos, asistencia psicológica y asesoría legal. iii) Manifiesta que en virtud del Art. 1 de la Convención Europea de Derechos Humanos toda persona que esté en la jurisdicción de un Estado miembro debe garantizar el ejercicio de los derechos humanos reconocidos en la Convención. iv) Menciona que a pesar de no estar reconocido de forma expresa el derecho a la salud en la Convención Europea de Derechos humanos, la Declaración Universal de derechos humanos es jurídicamente vinculante para los Estados miembros del Consejo de Europa y en su Art. $25 \mathrm{~N}^{\circ} 1$ reconoce el acceso a la asistencia médica y los servicios sociales necesarios para asegurar un nivel adecuado de salud y bienestar, en consecuencia, en caso de deportarlo se violaría su derecho a la salud pública. El TEDH manifiesta que es indispensable la exigibilidad del derecho a la salud de forma independiente, a pesar de no estar reconocido en la Convención Europea de Derechos Humanos. Así mismo señala que si bien Reino Unido ha cumplido con su obligación de no deportar a una persona con estado de salud delicada, no debe hacerlo, ya que caso contrario estaría incurriendo en un trato cruel, inhumano y degradante, que atenta contra su dignidad, la cual no la pierde, a pesar de haber cometido el delito de tráfico de drogas ilegales. El Sr. D es una persona vulnerable, pues sin la ayuda del Terrence Higgins Trust, organización encargada de brindar atención médica, asistencia psicológica y asesoría legal gratuita no contaría con recursos propios económicos, financieros, ni familia que se encargue de su cuidado, a su vez su propio estado de origen no puede garantizarle asistencia médica para su condición.

\subsection{Regional: Caso Gonzáles Lluy y otros vs. Ecuador sentencia emitida por la Corte IDH en el año de 2015.}

La niña Talía Gonzáles Lluy nació en 1995 en la ciudad de Cuenca provincia de Azuay, Ecuador, quien vive con sus padres y su hermano mayor. Cuando tenía tres años de edad, en 1998, fue contagiada con el virus de VIH al recibir una transfusión de sangre, del Banco de Sangre de la Cruz Roja, en una clínica privada (Hospital universitario católico de Cuenca). La Cruz Roja le indicó a la madre de Talía que debía traer donantes, la madre de Talia solicito a algunos 
conocidos entre ellos el Sr. HSA. La auxiliar de enfermera del banco de sangre de la cruz roja tomo las muestras de sangre del Sr. HSA y entregó las pintas a los familiares de Talia el 22 de junio de 1998. Un día más tarde la bioquímica de la Cruz Roja efectuó por primera vez exámenes de la muestra de sangre de HSA, incluyendo el de VIH, que dio positivo. Talia estuvo hospitalizada hasta el 29 de junio de 1998. El 22 de julio de 1998 se realizan exámenes de VIH a Talia y le informaron que el resultado era positivo. Al momento regio la Ley de aprovisionamiento y utilización de sangres y derivados, esta ley determinaba que la Cruz Roja tenía competencia exclusiva para administrar los bancos de sangre en Ecuador. Mediante Acuerdo ministerial 8664 de 1987 se estableció que todos los bancos de sangre del país, efectuaran pruebas de anticuerpo VIH, obligatoriamente en todas las unidades de sangre y sus derivados. Por lo tanto, la enfermera que tomo las muestras incumplió con la obligación de realizar las pruebas de forma oportuna, es decir antes de la transferencia. Talía y su familia han sufrido discriminaciones desde que se diagnosticó con VIH positivo tales como: i) Se le impidió a Talia estudiar en la escuela primaria, por su condición, violando su derecho a la educación. ii) Discriminación a su núcleo familiar al negarles el acceso a una vivienda, ya que fueron obligados a mudarse en múltiples ocasiones por "miedo a contagiarse de VIH".

La familia de Talia presentó el caso ante la CorteIDH con la pretensión de que se declare la responsabilidad del Estado de Ecuador por violación de los derechos humanos de Talia tales como: derecho a la vida (Art. 4), a la integridad personal (Art.5), derechos económicos sociales y culturales DESC (Art. 26) y al acceso a garantías judiciales y protección judicial (Art.8) reconocidos en la Convención Interamericana de Derechos Humanos de 1969. La CorteIDH resolvió el caso a la luz de la relación de la salud humana con los derechos a la vida e integridad personal, considera existe una evidente violación a dichos derechos, pues el Estado desde que la madre de Talia presento la acción judicial tenía conocimiento de su situación de vulnerabilidad interseccional ${ }^{32}$, sin

$32 \mathrm{La}$ CorteIDH se refiere a la discriminación de forma interseccional en el caso de Talia, porque confluyen varios factores sociales como la situación de pobreza de su familia (incluso presento un amparo de pobreza, que fue concedido), su situación de salud al ser una persona con VIH/sida es una persona estigmatizada y discriminada ( se le impidió el acceso a la educación por miedo al contagio) y al ser una niña se encuentra 
embargo, no recibió respuesta alguna. Es así que la CorteIDH en su análisis considera que el Estado ecuatoriano ha ignorado hasta el momento la situación de extrema vulnerabilidad de Talia impidiéndole vivir una vida digna, porque el solo hecho de brindar servicios de salud pública ineficientes, al no existir un mecanismo de control que prevenga violaciones al derecho a la salud en el sector privado, atentó contra la dignidad humana de Talia ${ }^{33}$. Así mismo considera que el servicio de salud pública puede ser ofrecido por los hospitales públicos o por la iniciativa privada, de forma complementaria y mediante la firma de convenios o contratos, por lo que también provee servicios de salud bajo los auspicios del Estado. En ambas situaciones, ya sea que el paciente esté internado en un hospital público o privado que tenga un convenio o contrato, la persona se encuentra bajo cuidado del Estado. Se sigue entonces que para garantizar el ejercicio del derecho a la vida y a la integridad personal es necesario gozar de un buen estado de salud (física, mental y social) y ejercer el derecho a la salud, que no sólo implica el acceso a los servicios de salud, sino que estos cumplan con ciertas características (disponibilidad, accesibilidad, adaptabilidad, calidad) que garanticen la dignidad de las personas y el ejercicio del derecho a la salud y otros derechos relacionados ( derecho a la vida y a la integridad personal). La Corte también considera pertinente recordar la interdependencia e indivisibilidad existente entre los derechos civiles y políticos y los derechos económicos, sociales y culturales, ya que deben ser entendidos integralmente como derechos humanos, sin jerarquía entre sí y exigibles en todos los casos ante aquellas autoridades que resulten competentes para ello ${ }^{34}$

Para ver los resúmenes completos de los casos analizados, dirigirse al Anexo

\footnotetext{
dentro de los grupos de atención prioritaria, a pesar de estas vulnerabilidades no se aplicó el principio de interés superior del niño. Sentencia Gonzales Lluy y otros vs. Ecuador CorteIDH, 2015, pp. 87-88, párr. 290.

33 "las obligaciones estatales frente al derecho a la integridad personal y frente a la necesidad de crear las condiciones para permitir una existencia digna, leídas conjuntamente con el deber de especial protección de la niñez y el principio de interés superior del niño o la niña, imponían al Estado dar una respuesta eficaz que debía materializarse en el acceso de [Talía] al tratamiento que requería" Caso Gonzales Lluy y otros vs. Ecuador CorteIDH, 2015, p. 43, párr. 156.

$34 \mathrm{La}$ CorteIDH ha establecido que el derecho a la integridad personal se halla directa e inmediatamente vinculado con la atención a la salud humana y que la falta de atención médica adecuada puede conllevar la vulneración del artículo 5.1 de la Convención. Corte Interamericana de Derechos Humanos. Caso Gonzales Lluy y otros vs. Ecuador, 2015, p. 47, párr.171-172
} 
1, cuadro 3 disponible en el siguiente link: https://sedesde.worldsecuresystems. com/anexo

Al analizar el caso internacional del Sr. D vs. Reino Unido de 1996 y el caso regional de Gonzáles Lluy y otros vs. Ecuador de 2015 se concluye que existen algunas semejanzas entre ambos, que se consideran son:

I. La fundamentación de ambos casos se basa en la violación al derecho a la vida, a la integridad personal y al acceso de recursos efectivos o garantías judiciales y protección judicial de los accionantes. ${ }^{35}$ Es decir no se lo encuadra en el derecho a la salud, esto se debe a que tanto en la Convención Europea de Derechos humanos de 1950 y en la Convención Americana de Derechos humanos de 1969, no se reconoce de forma expresa el derecho a la salud, pues es consecuencia del desarrollo histórico de los derechos humanos y su clasificación en generaciones, siendo el derecho a la salud de segunda generación. ${ }^{36}$

II. En ambos casos las partes actoras son personas vulnerables que han sufrido discriminación de forma interseccional, es decir que inciden varios factores como: su estado de salud deteriorado por una infección ocasionada por el virus del VIH, motivo por el cual fueron tratados de forma desigual, ninguno de los actores tiene los recursos económicos y financieros propios y suficientes para acceder a los servicios de salud pública, el Sr. D al haber cometido un delito es estigmatizado, mientras que Talia al ser una menor de edad necesita un trato que garantice el interés superior de ella. Es así que en ambos casos son personas que pertenecen a grupos de atención prioritaria y el Estado debe ser responsable en tomar acciones especiales e inmediatas, a través de políticas públicas, administrativas y legales que garanticen el ejercicio de los derechos fundamentales y la dignidad humana.

\footnotetext{
35 La Convención Europea de Derechos humanos reconoce el derecho a la vida, integridad personal y acceso a recurso efectivo en los Artículos 2, 3, 13, mientras que la Convención Americana reconoce esos derechos ya mencionados en los Artículos 4,5,8. Si bien existe diferencia en su nomenclatura la Convención Europea de Derechos humanos llama derecho a un recurso efectivo (Art.13) y prohibición de tortura (Art.3) en la Convención Americana de Derechos humanos se los llama acceso garantías jurisdiccionales y protección judicial (Art. 8) y derecho a la integridad personal (Art. 5) el fondo del concepto es el mismo.

36 Como se indicó en párrafos anteriores los DESC fueron positivados a partir de la década de los años 60 con el Pacto Internacional de DESC de 1966.
} 
III. En la resolución de los casos, a pesar que no se encuadro en la violación al derecho a la salud, ambas Cortes enfatizan la necesidad de dar un trato igualitario a los DESC y no jerarquizarlos o subordinarlos a los derechos civiles y políticos, ya que hay que realizar una interpretación contextual, evolutiva y literal de los derechos a la luz de los desarrollos doctrinarios contemporáneos, pues el derecho a la salud debe ser exigible y no debe ser interpretado de forma restrictiva. De acuerdo con los representantes, el contenido de los DESC debe interpretarse conforme la doctrina del Comité DESC y de otros instrumentos internacionales de derechos humanos vigentes como la Declaración Universal de DD. HH el PIDESC y en el caso regional del Protocolo de San Salvador.

IV. La interpretación del derecho a la salud en ambos casos señala que no implica únicamente el acceso a los servicios de salud pública y la libertad de elegir de los usuarios entre un prestador público o privado, va más allá, debido a que los servicios públicos deben cumplir con ciertos requisitos ( disponibilidad, adaptabilidad, accesibilidad y calidad) para que garanticen el ejercicio del derecho a la salud, los derechos relacionados o conexos ( derecho a la vida, a la integridad personal entre otros) y el respeto a la dignidad humana.

V. En cuanto a la dignidad humana, en los dos casos estudiados se considera un principio general del Derecho, cimiento de los derechos fundamentales sean los DESC o cualquier otro derecho, cuya función es actuar como estándar del ejercicio de los derechos fundamentales, entre ellos el derecho a salud, entonces para promover el ejercicio del derecho a la salud, es indispensable interpretarlo a la luz del principio de dignidad humana. A su vez los análisis de las Cortes señalan que no hay dignidad humana ni integridad personal sin salud (física, mental y social) y en las circunstancias de personas vulnerables, que son discriminadas de forma interseccional, por su estado de salud, situación económica, edad, etc. el Estado debe brindar una protección reforzada para garantizar el ejercicio de los derechos fundamentales y su dignidad humana, sin que se vean sometidos a discriminación o a acciones arbitrarias por entidades públicas o privadas. 


\section{La dignidad humana como eje transversal para ejercicio del derecho a la salud}

El concepto de dignidad humana está vinculado, de forma estrecha a la ética, como un valor, reconocido por diferentes culturas, pero es a partir de la Declaración Universal de Derechos Humanos de 1948, que se reconoce como principio legal "ius cogens" vinculante a los Estados miembros que han firmado y ratificado dicho instrumento internacional. ${ }^{37}$ Se sigue que el principio de dignidad humana es la base de los derechos fundamentales, que son garantizados por un Estado democrático y sus ciudadanos al reconocer y respetar la autonomía, libertad y razonamiento propio y de otros. ${ }^{38}$ La Declaración de Viena de 1993 al respeto señala que:

"Reconociendo y afirmando que todos los derechos humanos tienen su origen en la dignidad y el valor de la persona humana, y que este es el sujeto central de los derechos humanos y las libertades fundamentales, por lo que debe ser el principal beneficiario de esos derechos y libertades y debe participar activamente en su realización ",39

Los derechos fundamentales forman parte de los principios generales del derecho tal como señala la Proclamación de Teherán de 1968 en su numeral seis al decir que

"Los Estados deben reafirmar su firme propósito de aplicar de modo efectivo los principios consagrados en la Carta de las Naciones Unidas y en otros instrumentos internacionales en relación con los derechos humanos y las libertades fundamentales”.

37 Para Habermas la universalización del concepto de dignidad humana debe seguir a la individualización, es decir el reconocimiento de factores como la raza, género, etnia, posición económica que deben ser tomados en cuenta para garantizar el derecho a la dignidad humana. Jürgen, Habermas. El concepto de dignidad humana y la utopía realista de los derechos humanos. Diánoia, LV, número 64, mayo 2010, p.16

38 Para Kant esa capacidad de reconocer la libertad, autonomía y razonamiento propio y de otro es tener dignidad y se en sus palabras "tratar a sí mismo y a todos los demás nunca como un simple medio sino siempre al mismo tiempo como fines en sí mismos." Immanuel, Kant. Kant's moral philosophy. Estados Unido: The Chaucer press, 2003, p.74.

39 Declaración de Viena, 1993, preámbulo. 
(Proclamación de Teherán, 1968, Nº).

A partir de la Proclamación de Teherán de 1968 quedó claro que parte de los principios generales del derecho son los derechos humanos esto fue acatado por la mayoría de la doctrina, al respecto Bidart Campos menciona:

“La proclamación de Teherán del año 1968 viene a clausurar la discusión doctrinaria, porque declara obligatoria para la comunidad internacional la citada Carta Internacional de Derechos humanos. De tal modo esa comunidad internacional integrada por todos los Estados que son miembros de la ONU queda vinculada por tal declaración, que en conjunto con los pactos internacionales y regionales y las declaraciones sobre los derechos del hombre compone lo que la doctrina bien puede hoy considerar como parte de los principios generales del derecho internacional, y hasta como ius cogens. Es decir, los derechos humanos en el seno de las Naciones Unidas y de la comunidad internacional operan con la fuerza de orden público internacional" (Campos, 2012, p. 436)

Se infiere de esta cita que los derechos humanos reconocidos en la Carta internacional de derechos humanos de la ONU y los demás instrumentos internacionales de DD.HH. Son parte de los principios generales del derecho y son ius cogens, está es su característica más importante, que se analiza a continuación.

La característica de "ius cogens" o "jus cogens" es una expresión en latín o locución latina, que expresa el carácter imperativo de los derechos humanos, que son parte de los principios generales del derecho. ${ }^{40}$ Característica que también se reconoce en la Convención de Viena sobre el Derecho de los tratados de 1969, que establece que la característica "ius cogens" es "norma aceptada y reconocida por la comunidad internacional de Estados en su conjunto como norma que no admite acuerdo en contrario y que sólo puede ser modificada por una norma ulterior de derecho internacional general que tenga el mismo carácter" ${ }^{\prime 1}$

De estas citas se razona que el principio de dignidad humana es un principio general del derecho y fundamento de los derechos humanos. Así mismo los

40 Monroy, Cabra. Introducción al derecho. Colombia: Temis, 2008, p.150.

41 Convención de Viene sobre el derecho de los tratados, 1969, Art.53. 
derechos humanos reconocidos en la Carta Internacional de Derechos humanos de la ONU y en otros instrumentos de derechos humanos, a partir de la Proclamación de Teherán 1968 son parte de los principios generales del derecho, por lo tanto, la dignidad humana y los derechos humanos son normas imperativas o "ius cogens", de aplicación directa e inmediata para todos los Estados miembros.

A pesar que el principio de dignidad humana y los derechos humanos son principios generales del derecho se aplican de forma diferente, tal como señala la teoría contemporánea de los principios generales del derecho desarrollada y analizada por varios juristas como Ronald Dworkin, Robert Alexy, Manuel Atienza, entre otros, que establece una clasificación de los principios generales del derecho, que varía con cada autor. Sin embargo, tal como señala Manuel Atienza y Jorge Ruiz Mancero la clasificación de los principios generales del derecho, ya fue desarrollada por juristas como Dworkin y Alexy, entre otros y la mayoría de juristas coincide existen principios: 1) strictu sensu, que expresan valores superiores de un ordenamiento jurídico son fines. 2) principios directrices o mandatos de optimización que estipulan la obligación de perseguir determinados objetivos. Los principios en strictu sensu se deben cumplir de forma plena o se cumple o no se cumple ejemplo la dignidad humana, mientras que los principios directrices se cumplen de forma gradual, en el mayor grado posible, por su interdependencia con otras directrices, ya que se pretende lograr la consecución conjunta de varios objetivos. Para Manuel Atienza los principios en strictu sensu operan como razones finales, fin último, mientras que los principios directrices actúan para la consecución de varios objetivos y estipulan la obligación de seguir un determinado fin, es decir están subordinados a los principios en strictu sensu, que actúan como razones de corrección en casos difíciles. ${ }^{42}$

\section{Conclusiones}

\section{Principio de dignidad humana como criterio transversal para el}

42 Manuel Atienza y Jorge Ruiz Mancero, Las piezas del Derecho: Teoría de los enunciados jurídicos, Madrid, España: Ariel, 1996, pp. 5-11. 
ejercicio del derecho a la salud: Se concluye que la dignidad humana y el derecho a salud, son parte de los principios generales del derecho, cuya característica principal es ser "ius cogens" ( de aplicación directa e inmediata), no obstante, se considera que operan de diferente manera, conforme la clasificación de los principios generales del derecho de Manuel Atienza y Jorge Ruiz Mancero, ya que el principio de dignidad humana es un principio en strictu sensu, porque es el fin primordial que debe perseguir los derechos humanos, mientras que el derecho a la salud es un principio directriz para los sistemas de salud conformados por entidades públicas y privadas, que prestan servicios de salud. La dignidad humana al ser un principio en strictu sensu se cumple de forma plena, demostrando su influencia transversal al momento de interpretar los derechos fundamentales, entre ellos el derecho a la salud. Mientras que el derecho a la salud al ser un principio directriz busca la consecución de varios objetivos, de forma gradual en el mayor grado posible, como la accesibilidad, disponibilidad, adaptabilidad y calidad de los servicios de salud pública para todos los usuarios, demostrando su relación con el derecho a la seguridad social y el derecho a la libertad de los usuarios de elegir entre un servicio público y privado de salud, cuyo fin último en conjunto es garantizar el respeto a la dignidad humana.

2. Exigibilidad independiente del derecho a la salud: En la actualidad existe el reconocimiento de la autonomía de los DESC por parte de la oficina del Alto Comisionado para los Derechos Humanos ACNUDH y su Comité DESC, a través de varios instrumentos internacionales como la Proclamación de Teherán de 1968 en su numeral 13 y la Declaración de Viena de 1993 en su numeral 5, que señalan que los derechos humanos son universales, indivisibles e interdependientes, es así que la clasificación de los derechos fundamentales en generaciones de Karel Vasak tiene una utilidad pedagógica, pero no implica que jerarquice a los derechos humanos. Este criterio es aplicado por los tribunales internacionales como el TEDH en el caso analizado del Sr. D vs. Reino Unido y regional como el Caso Gonzalés Lluy y otros vs. Ecuador sentencia de la CorteIDH, que enfatizan en sus resoluciones la necesidad de que el derecho a la salud sea exigible plenamente y no dependa de encuadrar el caso en los derechos civiles y políticos (como el derecho a la vida e integridad personal) con el objetivo de hacer verdaderamente exigible el derecho a la salud. 
3. Alcance del derecho a la salud: el alcance del derecho a la salud implica el cumplimiento de elementos esenciales como disponibilidad, accesibilidad, adaptabilidad y calidad e incluye la libertad de cada usuario de decidir si escoge un servicio público o privado de salud, la libertad de controlar su cuerpo, el derecho a no ser sometido a torturas ni tratamientos y experimentos médicos no consensuales, el acceso a un seguro de salud e incluye la obligación del Estado de regular, fiscalizar y supervisar la prestación de servicios de salud en centros públicos y privados. Todo esto tomando en cuenta ciertos factores que influyen en el ejercicio del derecho a la salud como: edad, sexo, género, etnia, raza, disponibilidad de recursos económicos, discapacidades físicas y mentales y factores culturales, que al no ser tomados en cuenta pueden ocasionar discriminación interseccional. ${ }^{43}$

\author{
Anexos: \\ Para visualizar los cuadros por favor seguir el siguiente link: \\ https://sedesde.worldsecuresystems.com/anexo

\section{Lista de Abreviaturas:} \\ Comité de los Derechos Económicos, Sociales y Culturales de Naciones \\ Unidas (Comité DESC) \\ Corte Interamericana de Derechos Humanos (CorteIDH) \\ Derechos Económicos Sociales y Culturales (DESC) \\ Pacto Internacional de Derechos Económicos, Sociales y Culturales \\ (PIDESC) \\ Síndrome de inmune deficiencia (SIDA) \\ Tribunal Europeo de Derechos Humanos (TEDH)
}

43 Tal como sucede en los casos del Sr. D vs. Reino Unido sentencia del TEDH y en el caso Gonzáles Lluy y otros vs. Ecuador sentencia de la CorteIDH. 


\section{Bibliografía}

Aquino, Santo Tomas. (2001) Suma Teológica, Madrid, España: Biblioteca de autores cristianos.

Atienza, M. y Ruiz, J. (1996). Las piezas del Derecho: Teoría de los enunciados jurídicos. Madrid, España: Ariel.

Bill of rights 1689, recuperado el 15 de enero de 2017 de http://www.law. gmu.edu/assets/files/academics/founders/English_BillofRights.pdf

Bohórquez, V. y Aguirre, J. (noviembre, 2009) Las tensiones de la dignidad humana: conceptualización y aplicación en el derecho internacional de los derechos humanos. Revista Sur, V. 6, ํ11, pp.41-63.

Carbonell, M. (2013) Derechos humanos: origen y desarrollo. Quito, Ecuador: Librería jurídica Cevallos.

Comité DESC. (2000) El derecho al disfrute del más alto nivel posible de salud: 11/08/2000. E/C/12/2000/4, CESCR observación general. Consejo de derechos económicos y culturales, Proclamación de Teherán 1968.

Constitución de la República del Ecuador 2008.

Convención Americana de derechos humanos de 1969.

Convención para la eliminación de todas las formas de discriminación 1965.

Convención de Viena sobre el derecho de los tratados de 1969.

Convención Europea de Derechos humanos. Recuperada el 15 de enero de 2017 de http://www.echr.coe.int/documents/convention_spa.pdf Corte Interamericana de derechos humanos, Caso Gonzáles Lluy y otros vs. Ecuador 2015.

Declaración Universal de Derechos humanos de 1948.

Habermas, J. (2010). El concepto de dignidad humana y la utopía realista

de los derechos humanos, Diánoia, volumen LV, número 64, pp.3-25.

Kant, I. (2008). Kant's moral philosophy. Pennsylvania, Estados Unidos: The Chaucer Press.

Monroy, C. (2008). Introducción al derecho. Bogotá, Colombia: Temis. 
Navarro, L. (Eds.). (1884) Biblioteca Clásica Marco Tulio Cicerón Epistolas familiares, Tomo VI. Madrid, España: Central y estereotipia. Nogueira, H. (2006). El derecho a la igualdad ante la ley, la no discriminación y acciones positivas. Revista de derecho universidad católica del norte, V. 13, N², pp. 61-100

OMS: Glosario de promoción de la salud, 1998, recuperado el 15 de enero de 2017 de http://apps.who.int/iris/bitstream/10665/67246/1/ WHO_HPR _HEP 98.1 spa.pdf.

OMS, Documentos básicos de la OMS, (OMS, 48 ed. 2014) disponible en http://apps.who.int/gb/bd/PDF/bd48/basic-documents-48thedition-sp.pdf?ua=1\#page=7.

Pacto Internacional de Derechos Económicos Sociales y culturales (PIDESC) 1966.

Peces-Barba Martínez, G. (2003). La dignidad de la persona desde la filosofía del Derecho. Madrid, España: Dykinson.

Peces-Barba Martínez, G. (2015). Lecciones de derechos fundamentales. Madrid, España: Dykinson.

Pele, A. (2010). Modelos de la dignidad del ser humano en la edad media, Madrid, España: Universidad Calos III de Madrid.

Polo, M. (2010). Santilla, Ética y política de Locke: de los derechos fundamentales a los humanos sin derechos. Lima, Perú: Universidad San Martín de Porres editorial.

Primera Conferencia de derechos humanos, Proclamación de Teherán 1968.

Protocolo adicional de la Convención Americana de Derechos humanos "Protocolo de San Salvador" de 1978.

Quintero, D. La salud como derecho. Colombia: Panamericana formas e impresos, 2011.

Torre Díaz, J. (2008) Dignidad humana y bioética. Madrid, España: Universidad Pontifica Comillas.

Tünnermann C. (2007). Los derechos humanos: evolución histórica y reto educativo. ( 3 ed.) Caracas, Venezuela: Unidad regional de la UNESCO. 
Tribunal Europeo de Derechos Humanos (TEDH), Caso Sr. D vs. Reino Unido. Recuperado el 15 de enero de 2017 http://hudoc.echr.coe.int/ eng\#\{“itemid":[“001-58035”]\}. 